\title{
Rapid Detection of Phytophthora ramorum and $P$. kernoviae by Two-Minute DNA Extraction Followed by Isothermal Amplification and Amplicon Detection by Generic Lateral Flow Device
}

\author{
J. A. Tomlinson, M. J. Dickinson, and N. Boonham
}

First and third authors: The Food and Environment Research Agency, Sand Hutton, York YO41 1LZ, United Kingdom; and second author: University of Nottingham School of Biosciences, Sutton Bonington Campus, Loughborough LE12 5RD, United Kingdom. Accepted for publication 20 October 2009.

\begin{abstract}
Tomlinson, J. A., Dickinson, M. J., and Boonham, N. 2010. Rapid detection of Phytophthora ramorum and P. kernoviae by two-minute DNA extraction followed by isothermal amplification and amplicon detection by generic lateral flow device. Phytopathology 100:143-149.

A method for nucleic-acid-based detection of pathogens in plant material has been developed which comprises a simple and rapid method for extracting DNA on the nitrocellulose membranes of lateral-flow devices, loop-mediated isothermal amplification (LAMP) of target DNA

cation products by a sandwich immunoassay in a lateral-flow-device format. Each of these steps can be performed without specialist equipment and is suitable for on-site use, and a result can be obtained in just over an hour. A LAMP assay for the detection of plant DNA (cytochrome oxidase gene) can be used in conjunction with pathogen-specific assays to confirm negative results. The use of this method is demonstrated for the detection of Phytophthora ramorum, the causal agent of sudden oak death and dieback/leaf blight in a range of tree, shrub, and herbaceous species, and the recently described pathogen $P$. kernoviae.
\end{abstract} using labeled primers, and detection of the generically labeled amplifi-
Efficient detection of pathogens in plant material is necessary for the timely implementation of eradication and containment measures to prevent or limit the spread of plant diseases that can have severe economic and sociological consequences. Plant pathogens can be detected using a range of methods, including examination of symptoms or pathogen morphology, antibody-based methods such as enzyme-linked immunosorbent assay, and nucleicacid-based methods (36). Polymerase chain reaction (PCR)-based detection methods are often favored for their sensitivity and specificity $(23,36)$.

However, in order for samples to be subjected to PCR-based testing, they need to be sent to a laboratory with the necessary facilities. Significant advantages could be gained from moving testing closer to the site of sampling and, thereby, reducing the delay between taking a sample and obtaining a result; however, the majority of nucleic-acid-based pathogen-detection methods are too complex and time consuming for reliable routine use outside the laboratory. In addition, PCR-based detection methods generally require the extraction of high-quality nucleic acid from the sample material, and this step is often found to be a bottleneck in terms of the time and operator skill required (23).

Methods for pathogen detection in the field, as well as being sufficiently sensitive and specific, should also be rapid and simple, with results that are easy to interpret, and should demand minimal equipment and facilities. In addition to these features, field-testing methods should ideally be inexpensive, and the components should be disposable or easily decontaminated. With these requirements in mind, PCR-based methods have a number of drawbacks which limit the feasibility of their use in field conditions. In particular, PCR-based methods require relatively

Corresponding author: J. A. Tomlinson;

E-mail address: jenny.tomlinson@fera.gsi.gov.uk

doi:10.1094/PHYTO-100-2-0143

(c) 2010 British Crown Copyright complex and expensive thermal-cycling equipment, particularly for real-time PCR, in which fluorescence detection is performed concurrently with thermal cycling. Real-time PCR can be performed in the field using portable, ruggedized platforms such as the Cepheid SmartCycler or Idaho R.A.P.I.D. $(18,29,34)$ but cost and complexity may limit the applications for which these platforms are appropriate.

In contrast to PCR, isothermal amplification methods avoid the use of thermal-cycling equipment, allowing reactions to be incubated in a water bath or simple heated block (9). Loopmediated isothermal amplification (LAMP) is an amplification method which uses two sets of primers (internal and external primers) and a DNA polymerase with strand-displacing activity to produce amplification products containing loop regions to which further primers can bind, allowing amplification to continue without thermal cycling $(25,27)$. Amplification is accelerated by the use of an additional set of primers (loop primers) that bind to those loops which are of the incorrect orientation for the internal primers to bind (24). A high level of specificity results from the requirement for primers to bind to up to eight regions of the target sequence, and the efficient generation of large amounts of amplification product permits the use of novel product detection methods (22). The use of LAMP has previously been described for the detection of a range of plant pathogens $(6-8,26,32,33,35)$.

LAMP products can be detected by conventional agarose gel electrophoresis, by the use of spectrophotometric equipment to measure turbidity (21), in real-time using intercalating fluorescent dyes (17), or by visual inspection of turbidity or color changes $(13,22)$. Although detection methods based on visual inspection have the advantage of requiring no equipment, assessment of color or turbidity with the unaided eye is potentially subjective. Equipment-free methods for unambiguous detection of LAMP products would increase the feasibility of using LAMP for detection of phytopathogens outside the laboratory. One such method is the use of lateral-flow devices (LFDs) for the detection of labels incorporated into the amplification products (15), a 
technique sometimes referred to as nucleic acid lateral flow (NALF).

Tests in an LFD format have a number of advantages for use in the field, and specific LFD immunoassays have been extremely successful in areas of point-of-care and on-site testing, including for the detection of plant pathogens $(3,16)$. However, the development of pathogen-specific immunoassays in LFD format requires the availability of suitable antibodies, the generation of which can be expensive and time consuming. Furthermore, the resulting immunoassays may not be sufficiently sensitive for reliable use in the field or sufficiently specific to identify the pathogen to the required taxonomic level. Nevertheless, the success of LFD-based diagnostic tests is an indicator of the ease with which these devices can be used and their results interpreted. Familiarity with this type of test could help to facilitate the adoption of nucleicacid-based detection methods in an LFD format for use by nonlaboratory staff.

Phytophthora ramorum (38) is the causal agent of mortality of tanoak (Lithocarpus densiflorus (Hook. \& Arn.) Rehd.) and Quercus spp. (sudden oak death) in forests on the west coast of the United States (28), and dieback and leaf blight in a wide range of plant species in Europe and elsewhere. P. kernoviae is a more recently described species (1) discovered in 2003 as the causal agent of a disease (with symptoms similar to $P$. ramorum) on rhododendron and beech trees in southwest England. LFDs are available for detection of Phytophthora spp. (16) and these have been successfully deployed in the field but, because these devices detect all members of the genus Phytophthora, further testing is required to identify the pathogen to the species level. Although genus-level identification is adequate for some applications, species-specific tests are required in some circumstances; for example, to discriminate between non-notifiable species and notifiable species such as $P$. ramorum and $P$. kernoviae. Rapid methods have been developed for detection of $P$. ramorum in the field $(33,34)$, although the use of thermal cycling equipment and the need for a suitably rapid DNA extraction method limit the use of these methods in field conditions.

The Food and Environment Research Agency has developed a method for the extraction of nucleic acid from LFDs (4). Amplifiable nucleic acid can be extracted from plant material in $<5$ min without the use of any equipment, making this method potentially suitable for use in the field. This article describes a simplified method for the detection of $P$. ramorum and $P$. kernoviae in infected plant material using an extremely rapid one-step DNA extraction method, followed by specific isothermal amplifycation, and detection of the amplification products in a generic and easily interpreted LFD format. The pathogen-specific assays are used in conjunction with an internal control assay for the detection of the cytochrome oxidase (COX) gene of the host plant, in order to confirm that DNA extraction was successful. A result can be obtained in just over $1 \mathrm{~h}$, with $<10 \mathrm{~min}$ of hands-on time and without the need for complex or expensive equipment.

\section{MATERIALS AND METHODS}

$P$. ramorum and $P$. kernoviae inoculation of plant material. Isolates of $P$. ramorum and $P$. kernoviae were grown on carrot piece agar (CPA) (38) for at least 1 week; then, $0.5-\mathrm{cm}^{2}$ agar plugs were taken from the leading edge of colonies and used to inoculate wounded detached leaves of Rhododendron 'Cunningham's White', which were incubated at room temperature in a damp chamber for at least 1 week.

DNA extracts for characterization of LAMP specificity and sensitivity. Isolates of Phytophthora spp. were grown on semiselective $\mathrm{P}_{5} \mathrm{ARP}-(\mathrm{H})$ agar (14) or CPA. DNA was extracted from $0.5-\mathrm{cm}^{2}$ plugs taken from the cultures using the NucleoSpin Plant kit (Machery-Nagel, Düren, Germany) following the manufacturer's protocol for fungi (12).
DNA was extracted from Phytophthora spp.-inoculated and uninoculated plant material $(\approx 0.5-\mathrm{g}$ samples) using the cetyltrimethylammonium bromide (CTAB)-based method used by Suarez et al. (31). DNA extracts were quantified by spectrophotometry and diluted in nuclease-free water.

Extraction of DNA using LFDs. DNA was extracted using LFDs in a process consisting of disruption of plant material in an extraction buffer followed by application of an aliquot of the buffer containing disrupted material to the release pad of the LFD, allowing it to run along the device's nitrocellulose membrane (4). DNA on the LFD membrane can be amplified by adding a section of the membrane directly to a DNA amplification reaction, such as LAMP. LFDs for DNA extraction were purchased from Forsite Diagnostics Ltd. (York, UK). Samples of leaf material $(0.3 \mathrm{~g})$ were placed in plastic bottles containing five steel ball bearings ( $5 \mathrm{~mm}$ in diameter) and $5 \mathrm{ml}$ of LFD Buffer C (Forsite Diagnostics Ltd.) and vortexed or shaken vigorously for $90 \mathrm{~s}$ to disrupt the sample material. This method results in sufficient disruption of the plant material for the release of DNA without complete homogenization of the sample (4). Buffer C $(70 \mu \mathrm{l})$ was transferred from the bottle to the release pad of the extraction LFD and allowed to flow across the membrane. The devices were allowed to dry at room temperature, typically for $\approx 5 \mathrm{~min}$ or, in some cases, for several hours. After this time, devices were stored in a sealed bag at room temperature.

LAMP primer design. LAMP primers for $P$. ramorum were as previously described (33). New LAMP primers were designed to detect $P$. kernoviae (based on the internal transcribed spacer sequence of a range of Phytophthora spp., as previously described by Hughes et al., 12), and an assay was designed for the detection of plant DNA based on COX sequence (37). Primer design was carried out using the LAMP primer design software PrimerExplorer V3. Six LAMP primers (external primers F3 and B3, internal primers FIP and BIP, and loop primers F-loop and Bloop) were designed for each assay. For details of the principle of the LAMP method, see Notomi et al. (27). Primers were synthesized by Sigma-Aldrich (Haverhill, UK); primer sequences are shown in Table 1.

LAMP. Extracted DNA $(1 \mu \mathrm{l})$ was added to $24 \mu \mathrm{l}$ of reaction mix, and negative controls containing nuclease-free water instead of DNA were included in each run. When LFDs were being tested, a section of the LFD membrane ( $\approx 5$ by $1 \mathrm{~mm}$ ) was added directly to the LAMP reaction mix. Sections were generally taken from the center of the membrane, although it is not necessary to sample from any particular region of the membrane (4). The $P$. ramorum and $P$. kernoviae LAMP reaction mixes consisted of Bst DNA polymerase (New England Biolabs, Ipswich, MA) at $0.32 \mathrm{U} / \mu \mathrm{l}, 1 \times$ Thermopol buffer (New England Biolabs), $1.4 \mathrm{mM}$ each dNTP, $6 \mathrm{mM} \mathrm{MgSO}_{4}$ (including $2 \mathrm{mM}$ in Thermopol buffer), $1.2 \mathrm{M}$ betaine, $200 \mathrm{nM}$ each external primer (F3 and B3), $2 \mu \mathrm{M}$ each internal primer (FIP and BIP), and $1 \mu \mathrm{M}$ each loop primer (F-loop and B-loop).

The plant COX LAMP reaction mix consisted of Bst DNA polymerase (New England Biolabs) at $0.64 \mathrm{U} / \mu \mathrm{l}, 1 \times$ Thermopol buffer, $1.4 \mathrm{mM}$ each dNTP, $8 \mathrm{mM} \mathrm{MgSO}_{4}$ (including $2 \mathrm{mM}$ in Thermopol buffer), $0.8 \mathrm{M}$ betaine, $400 \mathrm{nM}$ each external primer (F3 and B3), $4 \mu \mathrm{M}$ each internal primer (FIP and BIP), and $2 \mu \mathrm{M}$ each loop primer (F-loop and B-loop).

Reactions were incubated at $65^{\circ} \mathrm{C}$ for $60 \mathrm{~min}$, then at $80^{\circ} \mathrm{C}$ for 5 min to inactivate the $B s t$ polymerase. Amplification products were visualized by gel electrophoresis: LAMP products consist of products of different lengths containing alternately inverted repeats of the target sequence, appearing as a ladder-like pattern when visualized on a gel (27).

The COX LAMP assay was optimized using a range of concentrations of $\mathrm{MgSO}_{4}$ (4 to $10 \mathrm{mM}$ ), betaine $(0.8$ to $1.6 \mathrm{M})$, primers ( 0.2 to $4 \mu \mathrm{M})$, and $B s t$ polymerase $(0.32$ to $0.64 \mathrm{U} / \mu \mathrm{l})$. Optimal conditions were selected on the basis of the amount of product as 
assessed by gel electrophoresis (suboptimal conditions often resulted in no amplification). For assay optimization and characterization, reactions were carried out in duplicate.

LAMP using labeled primers. LAMP was carried out using labeled primers to allow detection of amplification products by LFD. For each assay, one loop primer (B-loop) was labeled at the $5^{\prime}$ end with biotin and the other loop primer (F-loop) was labeled at the $5^{\prime}$ end with either digoxigenin (DIG) ( $P$. ramorum and $P$. kernoviae assays) or fluorescein isothiocyanate (FITC) (COX assay). Labeled primers were synthesized by Eurofins MWG (Ebersberg, Germany).

Detection of labeled LAMP products by LFD. LFDs work by immunochromatography. The sample (labeled LAMP product in this case) is applied to the release pad of the device which contains colored latex coated with a reagent which specifically binds to the target molecule. The target-latex complex flows through the membrane to a test line containing a reagent which also binds to the target-latex complex, forming a visible line if the target is present. In this case, the reagent at the test line binds to one of the labels incorporated into the LAMP product (either DIG or FITC) and the latex binds to the other label (biotin). Therefore, a test line is formed only when both labels are incorporated into the amplification product; no test line is formed for negative reactions in which only unincorporated primers are present. The devices also have a control line containing a reagent which binds directly to the coated latex, such that a negative result is indicated by a single line (showing that the device has run successfully) and a positive results is indicated by two lines (Fig. 1). Devices for the detection of labeled LAMP products were purchased from Forsite Diagnostics. After amplification, the labeled LAMP reactions were diluted 1 in 500 in LFD Buffer C (Forsite Diagnostics); then, $\approx 70 \mu \mathrm{l}$ of diluted reaction was applied to the release pad of the device. The DIG/biotin devices and the FITC/biotin devices contained red and blue latex, respectively (Fig. 1).

Multiplex LAMP. LAMP reactions for multiplex detection of either $P$. ramorum and $\mathrm{COX}$ or $P$. kernoviae and $\mathrm{COX}$ were carried out using a reaction mix consisting of Bst DNA polymerase (New England Biolabs) at $0.32 \mathrm{U} / \mu \mathrm{l}$, $1 \times$ Thermopol buffer, $1.4 \mathrm{mM}$ each dNTP, $8 \mathrm{mM} \mathrm{MgSO}_{4}$ (including $2 \mathrm{mM}$ in Thermopol buffer), $0.8 \mathrm{M}$ betaine, $400 \mathrm{nM}$ each COX external primer, $4 \mu \mathrm{M}$ each COX internal primer, $2 \mu \mathrm{M}$ each COX loop primer, $200 \mathrm{nM}$ each pathogen external primer, $2 \mu \mathrm{M}$ each pathogen internal primer, and $1 \mu \mathrm{M}$ each pathogen loop primer.

Field samples. A small number of rhododendron samples were tested that had been collected by the Department for Environ- ment, Food and Rural Affairs (Defra) Plant Health and Seeds Inspectorate (York, UK) as part of ongoing surveillance for $P$. ramorum and $P$. kernoviae. Each sample was dispatched to the laboratory in a sealed plastic bag containing a small piece of damp tissue. On receipt in the laboratory, the material was examined for the presence of typical symptoms, and samples were taken from the leading edge of any identified lesions for routine diagnostic testing (isolation on $\mathrm{P}_{5} \mathrm{ARP}-(\mathrm{H})$ or detection by TaqMan real-time PCR) (12); duplicate samples were taken for extraction by LFD and testing by simplex LAMP using labeled primers, as described above.

\section{RESULTS}

P. kernoviae and COX LAMP assays. When visualized by agarose gel electrophoresis, the products of the P. kernoviae and COX assays showed the ladder-like pattern expected for LAMP products (Fig. 2). Amplification was not observed in the negative control reactions.

The lowest amount of $P$. kernoviae DNA to be consistently amplified using the $P$. kernoviae LAMP assay was $\approx 17$ pg (Fig. 2 ). This is comparable with the level of sensitivity observed for the $P$. ramorum LAMP assay developed previously (33). DNA extracts from cultures of other Phytophthora spp., including $P$.

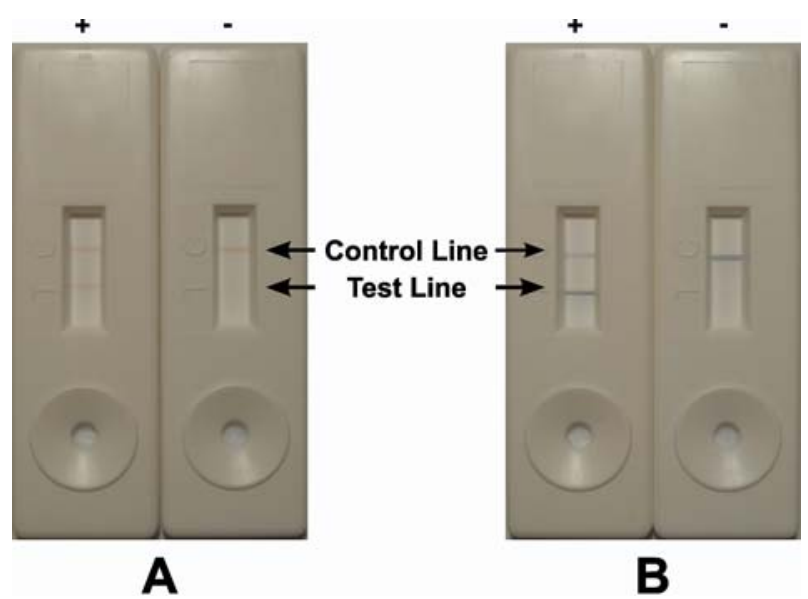

Fig. 1. Lateral flow devices for the detection of loop-mediated isothermal amplification products labeled with $\mathbf{A}$, digoxigenin and biotin or $\mathbf{B}$, fluorescein isothiocyanate and biotin, showing positive (+) and negative (-) results.

TABLE 1. Primers used for loop-mediated isothermal amplification

\begin{tabular}{|c|c|}
\hline Primer & Sequence $\left(5^{\prime}-3^{\prime}\right)$ \\
\hline Phytophthora ramorum $\mathrm{F} 3$ & CTAAAAAACTTTCCACGTGAAC \\
\hline P. ramorum $\mathrm{B} 3$ & CTTCATCGATGTGCGAGC \\
\hline$P$. ramorum FIP & TCAAGCGCTCGCCATGATAGAGTCAAAACCCTTAGTTGGGGGCT \\
\hline P. ramorum BIP & 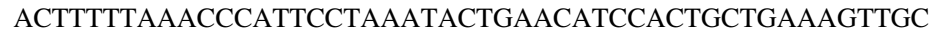 \\
\hline P. ramorum F-loop ${ }^{\mathrm{a}}$ & CGAAGCCAGCCGAACAGA \\
\hline P. ramorum B-loop ${ }^{b}$ & GTGGGGACGAAAGTCTCTG \\
\hline P. kernoviae $\mathrm{F} 3$ & TGTCGGCGACTAATTTCGTG \\
\hline P. kernoviae B3 & CGCATTGTCCGAAAACAACA \\
\hline P. kernoviae FIP & GCAGATTGTTCGGCCGAAACCCTGAGGCGTTTTGGAGAGG \\
\hline P. kernoviae BIP & TTCCTTGCTTTGGCGTTTGCGCGCACACAAAGTTTCGTTCA \\
\hline P. kernoviae F-loop ${ }^{\mathrm{a}}$ & CACTACCGCGAATCGAACC \\
\hline P. kernoviae B-loop ${ }^{\mathrm{b}}$ & TGGTGTACCGTAGTAGTGTGTAGCT \\
\hline Cytochrome oxidase (COX) F3 & TATGGGAGCCGTTTTTGC \\
\hline $\mathrm{COX} B 3$ & AACTGCTAAGRGCATTCC \\
\hline COX FIP & ATGGATTTGRCCTAAAGTTTCAGGGCAGGATTTCACTATTGGGT \\
\hline COX BIP & TGCATTTCTTAGGGCTTTCGGATCCRGCGTAAGCATCTG \\
\hline COX F-Loop ${ }^{c}$ & ATGTCCGACCAAAGATTTTACC \\
\hline COX B-Loop ${ }^{b}$ & GTATGCCACGTCGCATTCC \\
\hline
\end{tabular}

a 5 '-Labeled with digoxigenin when used with lateral-flow device (LFD) detection of loop-mediated isothermal amplification (LAMP) products.

b $5^{\prime}$-Labeled with biotin when used with LFD detection of LAMP products.

c 5'-Labeled with fluorescein isothiocyanate when used with LFD detection of LAMP products. 
boehmeriae, $P$. cactorum, $P$. cambivora, $P$. cinnamomi, $P$. citricola, and $P$. ramorum, were also tested and none of these species were amplified by the P. kernoviae LAMP assay (data not shown).

The lowest amount of rhododendron DNA to be consistently amplified using the COX LAMP assay was $\approx 9$ ng (Fig. 2). Amplification was also sometimes observed with $900 \mathrm{pg}$ of rhododendron DNA (Fig. 2), indicating that this is close to the limit of detection for this assay. The COX LAMP assay was also used to amplify DNA extracted from viburnum and camellia, two other commonly encountered hosts of $P$. ramorum in the United Kingdom (Fig. 2).

Labeled LAMP and LFD detection of labeled LAMP products. The use of labeled primers did not adversely affect any of the assays tested as determined by gel electrophoresis of the products (data not shown). DIG/biotin- and FITC/biotin-labeled LAMP products were run on DIG or FITC LFDs as appropriate, and the LFD results were consistent with the results of gel electrophoresis (Fig. 3). LFD test lines developed in $<5 \mathrm{~min}$, and control lines were observed for all devices.

Multiplex LAMP. The $P$. ramorum LAMP assay was used in multiplex with the COX LAMP assay to test CTAB DNA extracts from healthy and $P$. ramorum-infected rhododendron and an extract from $P$. ramorum culture. The multiplex products were run on DIG and FITC LFDs, demonstrating the detection of single products ( $P$. ramorum or COX) and mixed products (Fig. 4A).

The $P$. kernoviae LAMP assay was also used in multiplex with the COX assay to test extracts from $P$. kernoviae culture and healthy and $P$. kernoviae-infected rhododendron. In this case, the infected rhododendron failed to generate a positive $\mathrm{COX}$ result (Fig. 4B), although P. kernoviae was amplified from this sample. Pathogen DNA and plant DNA was amplified when the same extract was tested with the assays in separate tubes (data not shown). Subsequent experiments testing different ratios of $P$. kernoviae and plant DNA suggested that these assays used in multiplex could simultaneously amplify both targets unless one of the targets was present in excess (data not shown). Because the ratio of Phytophthora DNA to host DNA could vary considerably between samples of infected material, it is preferable to use the

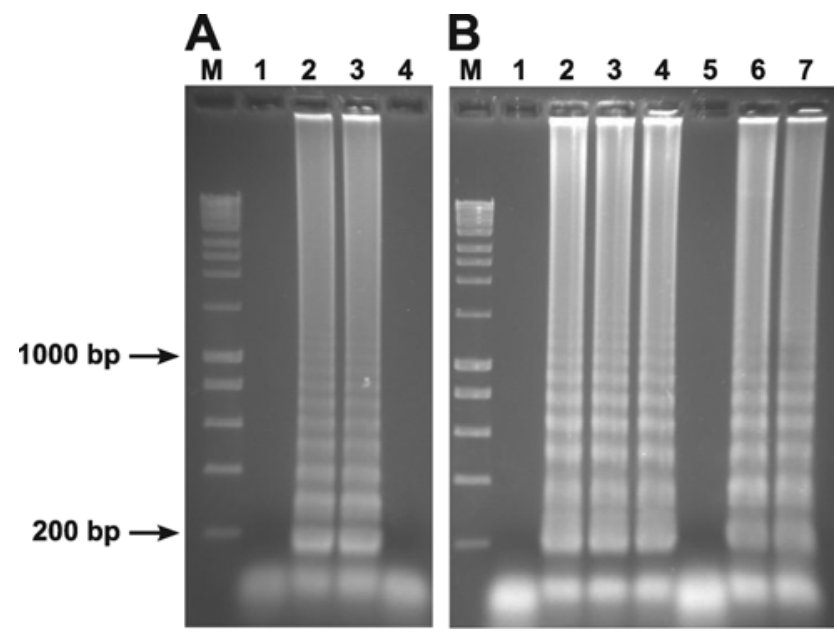

Fig. 2. Loop-mediated isothermal amplification (LAMP) for the detection of Phytophthora kernoviae and plant cytochrome oxidase (COX) gene. A, Dilutions of $P$. kernoviae DNA were amplified by P. kernoviae LAMP and the products were visualized by gel electrophoresis. M: marker (HyperLadder I) (New England Biolabs); lane 1: no-template control; lane 2: $170 \mathrm{pg}$ of $P$. kernoviae DNA; lane 3: $17 \mathrm{pg}$ of P. kernoviae DNA; lane 4: of $1.7 \mathrm{pg} P$. kernoviae DNA. B, Dilutions of rhododendron DNA and DNA extracted from viburnum and camellia were amplified by COX LAMP and the products were visualized by gel electrophoresis. M: marker; lane 1: no-template control; lane 2: $90 \mathrm{ng}$ of rhododendron DNA; lane 3: $9 \mathrm{ng}$ of rhododendron DNA; lane 4: $900 \mathrm{pg}$ of rhododendron DNA; lane 5: $90 \mathrm{pg}$ of rhododendron DNA; lane 6: viburnum DNA ( $\approx 100 \mathrm{ng})$; lane 7 : camellia DNA ( $\approx 100 \mathrm{ng})$. host and pathogen assays in separate tubes to avoid the situation in which a low level of pathogen is not detected due to the presence of a large amount of plant DNA, or the potentially less serious situation where the presence of a large amount of pathogen DNA results in failure to amplify the plant DNA (Fig. 4).

LFD extraction method. The ability of the detection method comprising LFD DNA extraction followed by (simplex) LAMP using labeled primers and analysis of the LAMP products using generic DIG and FITC LFDs was examined in terms of the ability to detect $P$. ramorum or $P$. kernoviae in infected rhododendron leaves. Necrotic material from inoculated leaves of rhododendron 'Cunningham's White' was mixed with healthy rhododendron leaf to produce samples with a total weight of $0.3 \mathrm{~g}$ containing $10 \%$ necrotic tissue by weight, and DNA was extracted by vortexing or vigorous shaking with ball bearings in LFD Buffer C for $90 \mathrm{~s}$ before application to LFDs. No difference was observed between samples disrupted by vortexing and by manual shaking. The LFDs were tested by LAMP either for $P$. ramorum and plant DNA (COX) or for P. kernoviae and COX, depending on the pathogen with which the samples had been inoculated. Typical results are shown in Figure 5: positive COX results were obtained for both infected and noninfected samples, $P$. ramorum was detected in the $P$. ramorum-infected material, and $P$. kernoviae was detected in the $P$. kernoviae-infected material. Results for replicate samples of healthy and inoculated rhododendron tested in this way are shown in Table 2. The same results were obtained for 10 replicate samples of healthy rhododendron and 10 replicate samples of $P$. kernoviae-inoculated rhododendron. In all, 7 of 10 samples con-

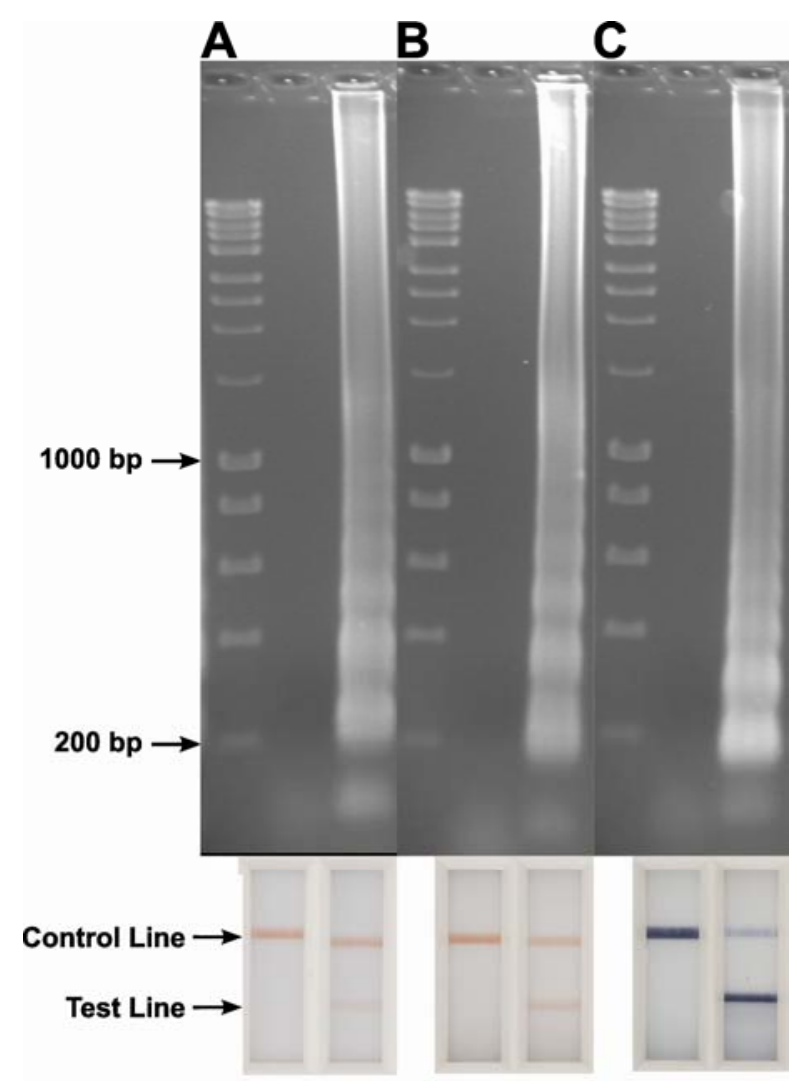

Fig. 3. Detection of labeled loop-mediated isothermal amplification (LAMP) products by gel electrophoresis (top) and lateral flow device (bottom). The same labeled LAMP products shown in the gel electrophoresis pictures were diluted and run on the devices shown below each lane. A, Phytophthora ramorum LAMP assay (digoxigenin [DIG] and biotin labels). Marker (HyperLadder I) (New England Biolabs); lane 1: no-template control; lane 2: $P$. ramorum DNA. B, $P$. kernoviae LAMP assay (DIG and biotin labels). Marker; lane 1: no-template control; lane 2: P. kernoviae DNA. C, Plant cytochrome oxidase LAMP assay (fluorescein isothiocyanate and biotin labels). Marker; lane 1: no-template control; lane 2: rhododendron DNA. 
taining $10 \% P$ ramorum-infected rhododendron tested positive for $P$. ramorum, and all tested positive for COX. This suggests that the amount of $P$. ramorum DNA extracted from these samples was close to the limit of detection for this assay. In total, 10 of 10 samples containing $20 \%$ P. ramorum-infected rhododendron were positive for both $P$. ramorum and COX.

In addition to testing artificially inoculated rhododendron, a small number of naturally infected samples collected in the field were tested using the same method (Table 3 ). The results for these samples concurred with those obtained by routine laboratory testing (isolation on $\mathrm{P}_{5} \mathrm{ARP}-(\mathrm{H})$ or detection by TaqMan real-time PCR) (12).

\section{DISCUSSION}

The pathogen detection method described here attempts to address some of the main requirements of on-site testing. The workflow is relatively simple in comparison with many existing nucleic-acid-based detection methods and generates results in an easily interpreted format in just over $1 \mathrm{~h}$, including DNA extraction. In addition, the LAMP reaction mix can be prepared in advance and lyophilized to allow room-temperature storage. Each of the three steps (manual shaking to disrupt the sample before application onto the DNA extraction LFD, placing a section of LFD membrane into pre-prepared LAMP reaction mix and incubation in a heated block or water bath, and dilution of the LAMP reaction and application onto the detection LFDs) is sufficiently simple to potentially allow this method to be performed outside a conventional laboratory facility without extensive prior training. Previous methods for nucleic-acid-based detection of plant pathogens in the field have sought to transfer established laboratory methods (for example, magnetic beadbased DNA extraction followed by real-time PCR) into a nonlaboratory environment $(11,34)$. However, methods that more specifically address the requirements for fewer steps using minimal equipment have the potential to be adopted in a wider range of settings. This method also compares favorably with existing methods in terms of the costs of DNA extraction and LAMP reagents. The cost of consumables required for LFD extraction of DNA (LFDs and buffer bottles) is similar to or less than the cost of commonly used extraction kits based on spin columns or magnetic beads, without taking into account the staff time and equipment required to use these kits. Primers labeled with DIG, FITC, and biotin can cost several times more per batch than unmodified oligonucleotides (equivalent to several pence per reaction) and typically cost approximately half the price (per reaction) than the fluorescently labeled oligonucleotide probes required for real-time PCR. In addition, the internal primers FIP and BIP require high-performance liquid chromatography purification due to their length. Therefore, the per-reaction cost of labeled LAMP is broadly comparable with real-time PCR. A typical small lab carrying out nucleic acid extraction by conventional methods followed by PCR or real-time PCR might be expected to be equipped with some or all of the following: water bath or heated block, centrifuge, vortexor, pipettors, refrigerated and frozen storage for reagents and samples, thermal cycler, equipment for gel electrophoresis, and real-time PCR instrument. Of these, however, only a water bath or heated block and pipettors (as well as a scalpel or similar instrument for cutting the DNA extraction LFD membranes) are required to carry out the method described in this article.

LFDs can be valuable tools for on-site pathogen detection, and the speed and simplicity of tests in this format have promoted adoption of this technology $(3,16)$. However, some pathogendetection LFDs have limitations in terms of their specificity or sensitivity. The pathogen-detection method that we describe could be used in conjunction with existing LFD immunoassays to mitigate these limitations. For example, labeled LAMP could be used to increase the specificity of pathogen detection in cases where it has not been possible to produce sufficiently specific antibodies. Species-specific antibodies are not available for $P$.

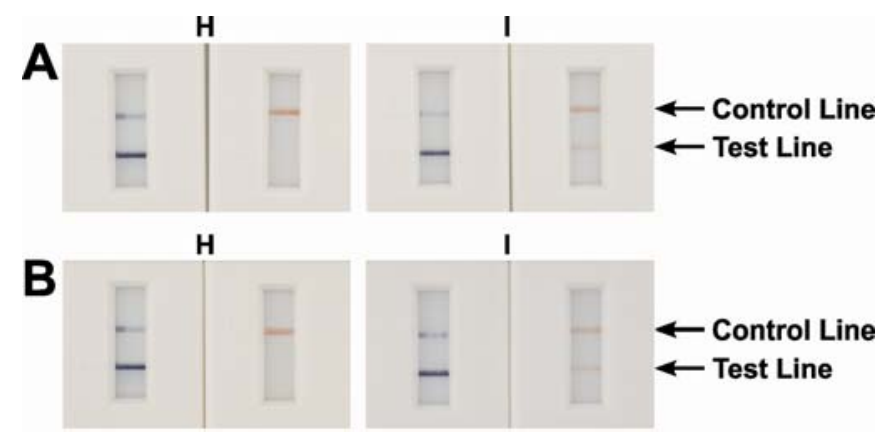

Fig. 5. Detection of A, Phytophthora ramorum and B, P. kernoviae in infected rhododendron leaf. DNA was extracted using lateral flow devices (LFDs) from samples of either healthy rhododendron leaf or rhododendron leaf mixed with P. ramorum- or P. kernoviae-infected rhododendron leaf to give $10 \%$ infected material by weight. LFDs were tested by labeled loop-mediated isothermal amplification (not in multiplex) for cytochrome oxidase (fluorescein isothiocyanate [FITC] and biotin labels) and either P. ramorum or P. kernoviae (digoxigenin [DIG] and biotin labels), respectively. The amplification products were applied to DIG/biotin and FITC/biotin LFDs. H: healthy rhododendron; I: infected rhododendron (10\% infected material by weight). FITC/ biotin devices shown on left (blue), DIG/biotin devices shown on right (red).

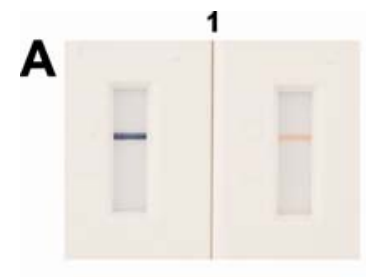

1

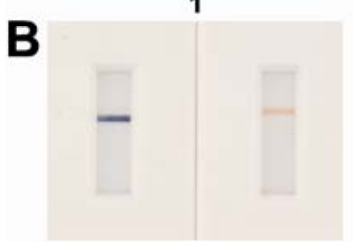

2

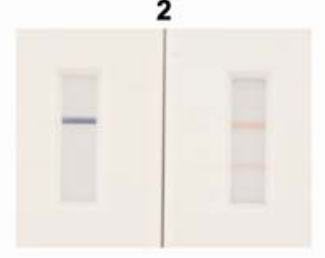

2

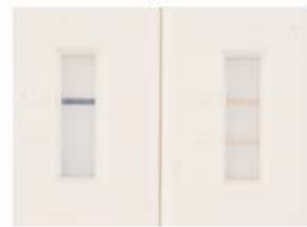

3

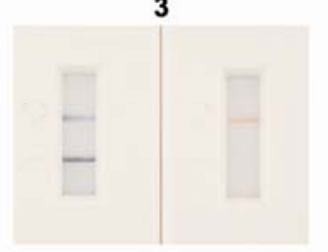

3

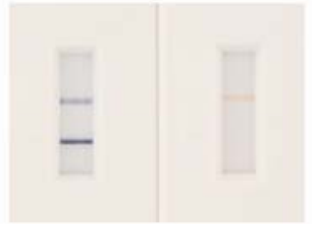

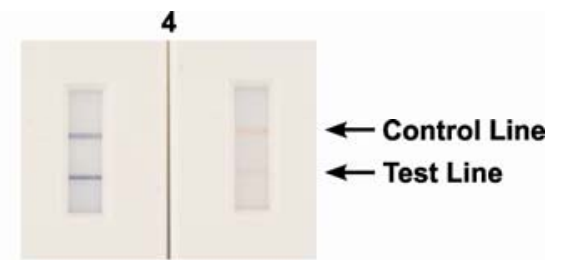

4

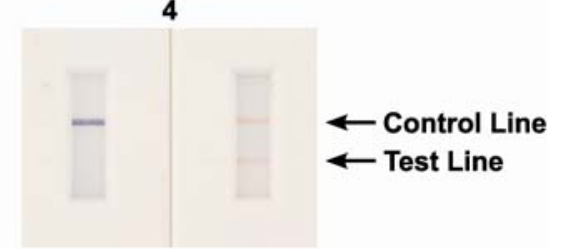

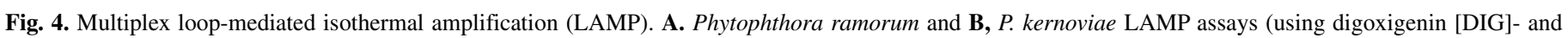

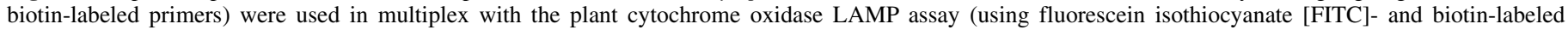

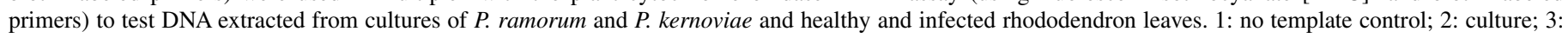
healthy rhododendron; 4: infected rhododendron. FITC/biotin devices shown on left (blue), DIG/biotin devices shown on right (red). 
ramorum or $P$. kernoviae but LFDs are currently available that detect all species of the genus Phytophthora (16). The labeled LAMP-LFD method could be used to test any positive devices to determine whether the Phytophthora sp. detected by the device is a particular species of interest (for example, $P$. ramorum or $P$. kernoviae, or any species for which a LAMP assay had been designed). For other pathogens, conventional LFDs may be available that are specific but insufficiently sensitive to detect the target pathogen in some samples. The labeled LAMP-LFD method could be used to test any samples that were negative by conventional LFD, in order to detect a pathogen below the detection threshold of the initial test. Finally, in applications where no LFDs are currently available, the development of a LAMP assay for the pathogen of interest could be considerably less costly and time consuming than the development of target-specific antibodies.

A particular hurdle for the development of field-testing methods for some plant pathogens is the requirement for the extraction of high-quality nucleic acid. Extraction methods selected for use in the laboratory may be favored for their low cost, high throughput, or amenability to automation. However, methods which have been developed with these requirements in mind are unlikely to be suitable for use outside the laboratory. Our previously described method for extraction of DNA from $P$. ramorum-infected plants using magnetic beads and a PickPen device (Bio-Nobile, Turku, Finland) could be completed in $\approx 30 \mathrm{~min}$ and involved a number of pipetting steps (34). Although this method was more rapid and required less equipment than many conventional laboratory-based methods (which often require multiple incubation and centrifugation steps or the use of organic solvents), the feasibility of using this method in some non-laboratory situations is limited. In comparison, the LFD nucleic-acid-extraction method is completed in $<5 \mathrm{~min}$ and the samples can be disrupted by manual shaking. After extraction has been carried out in the field, the devices can be tested at the point of sampling but, because DNA is stable on the LFD membrane at room temperature (4), it is also possible to return the devices to a laboratory for testing. This approach may be preferable to moving potentially infected plant material away from the site of sampling, and also expedites testing at the laboratory because the devices

TABLE 2. Summary of results for samples of healthy and artificially inoculated rhododendron tested by lateral-flow device (LFD) DNA extraction followed by labeled loop-mediated isothermal amplification (LAMP) and LFD detection of LAMP products

\begin{tabular}{lccc}
\hline & \multicolumn{3}{c}{ No. of samples positive/number of samples tested } \\
\cline { 2 - 4 } Sample type & COX & Phytophthora ramorum & P. kernoviae \\
\hline Healthy rhododendron & $10 / 10$ & $0 / 10$ & $0 / 10$ \\
$P$. ramorum $(10 \%)^{\mathrm{b}}$ & $10 / 10$ & $7 / 10$ & $\mathrm{n} / \mathrm{t}$ \\
P. ramorum $(20 \%)^{\mathrm{b}}$ & $10 / 10$ & $10 / 10$ & $\mathrm{n} / \mathrm{t}$ \\
$P$. kernoviae $(10 \%)^{\mathrm{b}}$ & $10 / 10$ & $\mathrm{n} / \mathrm{t}$ & $10 / 10$ \\
\hline
\end{tabular}

${ }^{a}$ LAMP result with LFD detection of product; COX = cytochrome oxidase; $\mathrm{n} / \mathrm{t}=$ not tested.

${ }^{\mathrm{b}}$ Percent infected material by weight (total sample weight $=0.3 \mathrm{~g}$ ). can be tested directly (for example, by real-time PCR) without further processing.

The final step in the workflow described in this article is the detection of labeled LAMP products using generic LFDs. The use of LFDs has been described for detection of the products of various nucleic-acid-amplification methods $(2,5,15,30)$. In some cases, the product is detected through the use of ampliconspecific capture or detector probes $(2,5)$. However, because these devices contain amplicon-specific oligonucleotides, it would be necessary to manufacture new devices for each target. The incorporation of labels which can be detected immunologically allows the use of generic devices for multiple applications, because the same labels can be incorporated in different assays (19). Incorporation of two labels allows the product to be detected in a sandwich format: generally, one label is incorporated into the amplification product using a labeled primer and the second label is incorporated using a labeled detector probe which hybridizes to the amplification product $(5,15,30)$. The detector probe is intended to ensure specificity of detection, because the amplicon must contain a sequence to which the detector probe will hybridize in order to produce a positive result. However, the amplification mechanism of LAMP confers inherent specificity because eight regions of the target sequence must be recognized for amplification to occur. We found that, by incorporating the second label into the amplification product using a second labeled primer, the required degree of specificity could be achieved without the need for any additional reagents.

Unlike gel electrophoresis, the use of intercalating dyes, and observation or measurement of turbidity, the LFD detection approach allows the resolution of mixed products generated by multiplex assays by using differently labeled primers in each assay. The plant COX assay was designed to assist in the interpretation of negative results by indicating the success or failure of DNA extraction, and the use of this assay is described here in multiplex with the pathogen-specific assays (Fig. 4) as well as in simplex (Figs. 2, 3, and 5). Whether the pathogen-specific and plant control assays should be used individually or in multiplex is likely to depend on the target pathogen and the plant matrices to be tested. The challenge of optimizing a robust multiplex reaction is compounded in the case of LAMP by the use of six primers for each assay. For applications where the ratio of pathogen DNA to plant DNA varies widely between samples, it is preferable to use the pathogen and COX assays in separate tubes to avoid failure to detect low levels of pathogen in the presence of large amounts of plant DNA. A pathogen-plant multiplex assay could be more easily optimized for applications where the ratio of pathogen to plant DNA is more predictable.

In order to detect LAMP products on the LFDs used here, it was necessary to dilute the products $\approx 1$ in 500 before applying them to the device. However, as has been discussed elsewhere $(20,33)$, opening the reaction tubes after amplification increases the risk of cross-contamination with previously amplified product (although, once diluted, the products pose less of a risk). The avoidance of contamination is likely to be the major challenge in the adoption of LAMP for routine use, especially outside the

TABLE 3. Summary of results for samples of naturally infected rhododendron tested by lateral-flow device (LFD) DNA extraction followed by labeled loopmediated isothermal amplification (LAMP) and LFD detection of products

LAMP result with LFD detection of product

\begin{tabular}{lcccc} 
Sample & Laboratory diagnosis $^{\mathrm{a}}$ & COX $^{\mathrm{b}}$ & Phytophthora ramorum & P. kernoviae \\
\hline 1 & P. ramorum & Positive & Positive & Negative \\
2 & P. ramorum & Positive & Positive & Negative \\
3 & P. kernoviae & Positive & Negative & Positive \\
4 & Negative & Positive & Negative & Negative \\
5 & Negative & Positive & Negative \\
\hline
\end{tabular}

${ }^{\text {a }}$ Result of laboratory testing for $P$. ramorum and P. kernoviae by isolation on semiselective media or TaqMan real-time polymerase chain reaction.

b Cytochrome oxidase. 
laboratory. A closed-tube method for the detection of labeled products of isothermal helicase-dependant amplification has been described (10). Modifications to the reported method to avoid any handling of the undiluted amplification products would help to make the method more robust.

Validation in comparison with established methods is required before the method described in this article could be used for a particular application. Although the sensitivity of a LAMP assay can approach that of real-time PCR, the LFD extraction method is somewhat less efficient than more laborious conventional methods. Nevertheless, the method described here was sufficiently sensitive for testing symptomatic Phytophthora spp.-infected rhododendron (mixed 1 in 10 or 1 in 5 with noninfected material), and the feasibility of testing naturally infected rhododendron has been demonstrated for a small number of samples. Further optimization of the DNA extraction method may be required for different sample types containing different levels of pathogen.

\section{ACKNOWLEDGMENTS}

This work was funded by Plant Health Division, Defra, project PH0424.

\section{LITERATURE CITED}

1. Brasier, C. M., Beales, P. A., Kirk, S. A., Denman, S., and Rose, J. 2005. Phytophthora kernoviae sp. nov., an invasive pathogen causing bleeding stem lesions on forest trees and foliar necrosis of ornamentals in the UK. Mycol. Res. 109:853-859.

2. Carter, D. J., and Cary, R. B. 2007. Lateral flow microarrays: a novel platform for rapid nucleic acid detection based on miniaturized lateral flow chromatography. Nucleic Acids Res. 35:e74

3. Danks, C., and Barker, I. 2000. On-site detection of plant pathogens using lateral-flow devices. OEPP/EPPO Bull. 30:421-426.

4. Danks, C., and Boonham, N. September 2007. Purification method and kits. Patent WO/2007/104962.

5. Deborggraeve, S., Claes, F., Laurent, T., Mertens, P., Leclipteux, T., Dujardin, J. C., Herdewijn, P., and Büscher, P. 2006. Molecular dipstick test for diagnosis of sleeping sickness. J. Clin. Microbiol. 44:2884-2889.

6. Fukuta, S., Iida, T., Mizumkami, Y., Ishida, A., Ueda, J., Kanbe, M., and Ishimoto, Y. 2003. Detection of Japanese yam mosaic virus by RT-LAMP. Arch. Virol. 148:1713-1720.

7. Fukuta, S., Kato, S., Yoshida, K., Mizukami, Y., Ishida, A., Ueda, J., Kanbe, M., and Ishimoto, Y. 2003. Detection of Tomato yellow leaf curl virus by loop-mediated isothermal amplification reaction. J. Virol. Methods 112:35-40.

8. Fukuta, S., Ohishi, K., Yoshida, K., Mizukami, Y., Ishida, A., and Kanbe, M. 2004. Development of immunocapture reverse transcription loopmediated isothermal amplification for the detection of Tomato spotted wilt virus from chrysanthemum. J. Virol. Methods 121:49-55.

9. Gill, P., and Ghaemi, A. 2008. Nucleic acid isothermal amplification technologies-a review. Nucleosides Nucleotides Nucleic Acids 27:224243.

10. Goldmeyer, J., Li, H., McCormac, M., Cook, S., Stratton, C., Lemieux, B., Kong, H., Tang, W., and Tang, Y. W. 2008. Identification of Staphylococcus aureus and determination of methicillin resistance directly from positive blood cultures by isothermal amplification and a disposable detection device. J. Clin. Microbiol. 46:1534-1536.

11. Hughes, K. J. D., Giltrap, P. M., Barton, V. C., Hobden, E., Tomlinson, J. A., and Barber, P. 2006. On-site real-time PCR detection of Phytophthora ramorum causing dieback of Parrotia persica in the UK. Plant Pathol. $55: 813$.

12. Hughes, K. J. D., Tomlinson, J. A., Griffin, R. L., Boonham, N., Inman, A. J., and Lane, C. R. 2006. Development of a one-step real-time polymerase chain reaction assay for diagnosis of Phytophthora ramorum. Phytopathology 96:975-981.

13. Iwamoto, T., Sonobe, T., and Hayashi, K. 2003. Loop-mediated isothermal amplification for direct detection of Mycobacterium tuberculosis complex, M. avium, and $M$. intracellulare in sputum samples. J. Clin. Microbiol. 41:2616-2622.

14. Jeffers, S. N., and Martin, S. B. 1986. Comparison of two media selective for Phytophthora and Pythium species. Plant Dis. 70:1038-1043.

15. Kiatpathomchai, W., Jaroenram, W., Arunrut, N., Jitrapakdee, S., and Flegel, T. W. 2008. Shrimp Taura syndrome virus detection by reverse transcription loop-mediated isothermal amplification combined with a lateral flow dipstick. J. Virol. Methods 153:214-217.
16. Lane, C. R., Hobden, E., Walker, L., Barton, V. C., Inman, A. J., Hughes, K. J. D., Swan, H., Colyer, A., and Barker, I. 2007. Evaluation of a rapid diagnostic field test kit for identification of Phytophthora species, including $P$. ramorum and $P$. kernoviae at the point of inspection. Plant Pathol. 56:828-835.

17. Maeda, H., Kokeguchi, S., Fujimoto, C., Tanimoto, I., Yoshizumi, W., Nishimura, F., and Takashiba, S. 2005. Detection of periodontal pathogen Porphyromonas gingivalis by loop-mediated isothermal amplification method. FEMS Immunol. Med. Microbiol. 43:233-239.

18. Mavrodieva, V., Levy, L., and Gabriel, D. W. 2004. Improved sampling methods for real-time polymerase chain reaction diagnosis of citrus canker from field samples. Phytopathology 94:61-68.

19. Mens, P. F., van Amerongen, A., Sawa, P., Kager, P. A., and Schallig, H. D. F. H. 2008. Molecular diagnosis of malaria in the field: development of a novel 1-step nucleic acid lateral flow immunoassay for the detection of all 4 human Plasmodium spp. and its evaluation in Mbita, Kenya. Diagn. Microbiol. Infect. Dis. 61:421-427.

20. Mori, Y., Hirano, T., and Notomi, T. 2006. Sequence specific visual detection of LAMP reactions by addition of cationic polymers. BMC Biotechnol. 6:3.

21. Mori, Y., Kitao, M., Tomita, N., and Notomi, T. 2004. Real-time turbidimetry of LAMP reaction for quantifying template DNA. J. Biochem. Biophys. Methods 59:145-157.

22. Mori, Y., Nagamine, K., Tomita, N., and Notomi, T. 2001. Detection of loop-mediated isothermal amplification reaction by turbidity derived from magnesium pyrophosphate formation. Biochem. Biophys. Res. Commun. 289:150-154.

23. Mumford R., Boonham, N., Tomlinson, J., and Barker, I. 2006. Advances in molecular phytodiagnostics-new solutions for old problems. Eur. J. Plant Pathol. 116:1-19.

24. Nagamine, K., Hase, T., and Notomi, T. 2002. Accelerated reaction by loop-mediated isothermal amplification using loop primers. Mol. Cell. Probes 16:223-229.

25. Nagamine, K., Watanabe, K., Ohtsuka, K., Hase, T., and Notomi, T. 2001. Loop-mediated isothermal amplification reaction using a nondenatured template. Clin. Chem. 47:1742-1743.

26. Nie, X. 2005. Reverse transcription loop-mediated isothermal amplification of DNA for detection of Potato virus Y. Plant Dis. 89:605-610.

27. Notomi, T., Okayama, H., Masubuchi, H., Yonekawa, T., Watanabe, K., Amino, N., and Hase, T. 2000. Loop-mediated isothermal amplification of DNA. Nucleic Acids Res. 28:e63.

28. Rizzo, D. M., Garbelotto, M., Davidson, M., Slaughter, J. M., and Koike, G. W. 2002. Phytophthora ramorum as the cause of extensive mortality of Quercus spp. and Lithocarpus densiflorus in California. Plant Dis. 86:205-214.

29. Schaad, N. W., Opgenorth, D., and Gaush, P. 2002. Real-time polymerase chain reaction for one-hour on-site diagnosis of Pierce's disease of grape in early season asymptomatic vines. Phytopathology 92:721-728.

30. Srisala, J., Tacon, P., Flegel, T. W., and Sritunyalucksana, K. 2008. Comparison of white spot syndrome virus PCR-detection methods that use electrophoresis or antibody-mediated lateral flow chromatographic strips to visualize PCR amplicons. J. Virol. Methods 153:129-133.

31. Suarez, M. B., Walsh, K., Boonham, N., O’Neill, T., Pearson, S., and Barker, I. 2005. Development of real-time PCR (TaqMan) assays for the detection and quantification of Botrytis cinerea in planta. Plant Physiol. Biochem. 43:890-899.

32. Tomlinson, J., and Boonham, N. 2008. Potential of LAMP for detection of plant pathogens. In: CAB Reviews: Perspectives in Agriculture, Veterinary Science, Nutrition and Natural Resources 3: article 066.

33. Tomlinson, J. A., Barker, I., and Boonham, N. 2007. Faster, simpler, more-specific methods for improved molecular detection of Phytophthora ramorum in the field. Appl. Environ. Microbiol. 73:4040-4047.

34. Tomlinson, J. A., Boonham, N., Hughes, K. J. D., Griffin, R. L., and Barker, I. 2005. On-site DNA extraction and real-time PCR for detection of Phytophthora ramorum in the field. Appl. Environ. Microbiol. 71:6702-6710.

35. Varga, A., and James, D. 2006. Use of reverse transcription loop-mediated isothermal amplification for the detection of Plum pox virus. J. Virol. Methods 138:184-190.

36. Ward, E., Foster, S. J., Fraaije, B. A., and McCartney, H. A. 2004. Plant pathogen diagnostics: immunological and nucleic acid-based approaches. Ann. Appl. Biol. 145:1-16.

37. Weller, S. A., Elphinstone, J. G., Smith, N. C., Boonham, N., and Stead, D. E. 2000. Detection of Ralstonia solanacearum strains with a quantitative, multiplex, real-time, fluorogenic PCR (TaqMan) assay. Appl. Environ. Microbiol. 66:2853-2858.

38. Werres, S., Marwitz, R., Man in 't Veld, W. A., De Cock, W. A. M., Bonants, P. J. M., De Weerdt, M., Themann, K., Ilieva, E., and Baayen, R. P. 2001. Phytophthora ramorum sp. nov., a new pathogen on Rhododendron and Viburnum. Mycol. Res. 105:1155-1165. 